\title{
Research on Market Mode and Requirement of Reserve Ancillary Service for Interconnected Power System
}

\author{
Pingping Bai ${ }^{1,2, a}$, Zheliang $\mathrm{Li}^{1,2, \mathrm{~b}}$, Mu Zhu ${ }^{3, \mathrm{c}}$, Qiulu Wang ${ }^{4, \mathrm{~d}}$ \\ ${ }^{1}$ State Grid Henan Electric Power Company Luoyang Power Supply Company, \\ Luoyang 471000, China \\ ${ }^{2}$ School of Electrical Engineering, Wuhan University, Wuhan 430072, China \\ ${ }^{3}$ State Grid Henan Electric Power Company Maintenance Company, \\ Zhengzhou 450000, China \\ ${ }^{4}$ Luoyang City Planning and Architectural Design \& Research Institute Company. \\ Luoyang 471000, China \\ a935769881@qq.com, ${ }^{b} 1015903240 @ q q . c o m$
}

Keyword: Market mode, reserve ancillary service

\begin{abstract}
Reserve ancillary service is necessary to maintain the power system operation reliability. It is trended now to be procured under the deregulated environment in order to improve the enthusiasm of reserve ancillary service providers. Therefore, a reasonable reserve market mechanism in which all the necessary reserve capacity could be procured in an interconnected large scale power system is a problem desiderated to be studied. LOLP indicators based probabilistic methods to obtain alternate contrast, reduce backup capacity requirements, taking into account the reliability of the system, in the process of market-oriented operation of the standby for use probabilistic algorithm to determine the needs of the system backup, unified obtain alternate resources.
\end{abstract}

\section{Introduction}

Introduction of competition in the various aspects of the power system, increase vitality, has become the trend of countries in the world power industry development. In a just, fair and open principles establish the electricity market, and thus the electric power of free trade around the world are actively promoting. In order to meet the needs of the market economy, and actively promote the national network and the establishment of the electricity market has also become a strategic goal of China's power industry reform and development. Operating conditions of the electricity market to make the power system more complex, greatly increasing the unpredictability of the current distribution and stability, and security and stability issues will also be significantly restricting the development of interconnected power grid and electricity market. In the electricity market in order to avoid system instability due to one-sided pursuit of economic efficiency and bring urgently needed to maintain system reliability. Ancillary services as a major measure to ensure the system safe and stable operation, has attracted more and more attention.

Power system, the generator of random outages, load fluctuations, line failure, would undermine the balance of power system, appear less active, serious and even cause widespread power outages. So we must maintain a certain active standby. Alternate means to meet projected power system in addition to external load demand, in order to ensure power quality and system security and stability and to maintain the active reserves, it is an important part of ancillary services. Under normal circumstances, some backup provided by a generator, interruptible load also plays backup role. In general, the spare capacity, the reliability of the system is higher. 


\section{Regional Reserve Market Acquisition and Coupling Model}

Regional market existing market model main is focusing the regional energy market. Alternate access to resources means total demand in all units to provide ancillary services in adjustable capacity to make a purchase offer on the way to meet the requirements of the spinning reserve capacity be reserved. When the actual load and predicted load output deviation occurs or there is a vacancy in the system, to undertake ancillary services between the conduct of the standby unit called, namely active control mode, it can be hierarchical control area and cities, and provinces now TBC control mode.

Regional power grid currently required spare unified balance, so different operating mode, according to the regional electricity supply and demand and load, centralized access model and sub-provincial acquisition mode dispersion have their own advantages. Run down low, as the total system capacity is greater than the load demand, ample spare capacity, and therefore preferred EAST centralized acquisition mode; in peak operating mode, the system in short supply, spare capacity and be required to contribute to the unit reduce demand-side management can be achieved, and therefore points provinces and decentralized model slightly dominant.

Market concentration / focus on obtaining a replacement model is more economical, centralized market / partition standby mode get poor economy, but market concentration / focus on obtaining a replacement / partition between the minimum standby mode economy between the two modes. However, the model focused on obtaining basic spare resources in the area, to ensure that each sub-region to retain a certain amount of minimum alternate partition, both to reduce spare capacity purchase costs, but also to protect the safety and reliable operation of the power grid, and with the existing partition standby mode mechanism Similarly, easier to achieve.

Hydropower units divided according to whether they have the ability to regulate the market categories into standby, the unit has the ability to regulate directly as a Class A Units in reserve market bidding; no ability to regulate hydropower unit is entering the market as a price taker, power generation plan by the Province * City dispatch center has developed, it is not suitable to participate in reserve market bidding. Since the gas pressure gas turbine and other reasons, there is no condition to achieve the ability to regulate, and therefore not suitable to participate in the standby gas turbine market, market price taker participate reserve market, where the provincial power plan formulated by the dispatch center. Cogeneration and small-capacity thermal power units belong to this unit, or can be called self-arrangement unit provinces. Pocket load unit as Class B units still do not participate in market competition.

Ancillary services market clearing completely before the primary energy market coupling, participation ahead bidding transaction clearing requirements before the market clearing model in primary energy in each trading session, the total cost of the alternate minimum objective function, and to consider the unit to provide ancillary services opportunity cost, by the East China region with the safe operation of constraint optimization calculations clearing markets, generating plans and node price before the transaction, as well as ancillary services hourly clearing price plan of arrangement and ancillary services products. Optimization clearing model constraints need to add a backup demand constraint, AGC demand constraints.

Full participation in the secondary market clearing real-time mode, but still one hour clearing ancillary services once the system ISO updated real-time data unit (such as unit FM capacity, unit status) and the node price per hour to achieve primary energy and spare capacity Joint Optimization of clearing achieve a minimum total purchase cost of the target. Support services for all involved in the real-time market-clearing time and technical requirements of the market running higher, in real-time is relatively mature market operators could be considered ancillary services exclusively on real-time market.

The majority of reserve service for the needs of the trading volume on the day-ahead market, day-ahead market clearing result by the scheduled execution date of ancillary services program, reducing the pressure on real-time market operations. New York, Texas, California, have adopted 
the supplementary service while participating in day-ahead market, real-time market clearing model.

\section{Requirements of Interconnected Systems Spare Capacity}

The regional power grid independent operation of interconnected through the contact line is the general trend of the development of the contemporary system of power. From the reliability point of view, the system interconnect benefits are obvious. First of spare capacity of the two systems can support each other in case of failure, the reliability of the interconnected system, isolated high than running; on the other hand, if the level of interconnection maintain system reliability before and after the change, the system desired spare capacity can be reduced, thereby reducing the cost of obtaining the standby. This chapter focuses on the needs of the spare calculated by LOLP index, which assumes the interconnected system of both power generation equipment failures and load independent of each other and both sides of the system without affecting the normal power supply of the premise, if the capacity limit contact line may be all spare capacity to support other systems.

When two or more of the interconnected power system through the contact line, load shifting effect due to the load and spare capacity sharing and other reasons, the electric power generation system reliability has been significantly improved. And isolated system differs in that the following factors should be considered when analyzing the reliability of the interconnected system: the reliability of the data capacity of each system, the transmission capacity of the contact line between the isolated system, the contact line, such as failure rates and repair rate, load characteristics of each isolated system, the capacity of the system of mutual support between the various economic factors such as the economy contracts. For the first three factors only after other means to obtain the statistics. In the interconnected power system power shortage occurs, the support capacity can be obtained from other systems with other systems depends not only on how much spare capacity and contact lines allow transmission capacity, but also depend on the support contract, are generally shared spare capacity, there are shared insufficient power. Geographic area generally larger interconnected system, changes in the relative independence of each load model, while the year is divided into several periods load in each period, a wide range of load changes will not occur. Based on the above facts, it is assumed that the loading of the isolated system fully independent.

Backup requirements of the system should guarantee the necessary capacity of the system to normal operation. Reserve capacity needs of various alternate market also may be based on the unbalanced load. Traditional power system spare capacity size is specified by the regulations, such as in the power of the system technology guide states: "Accident spare capacity of about $10 \%$ of the maximum power load, but not less than a maximum capacity of the system unit." ; "load reserve capacity of $2 \%$ to $5 \%$ of the maximum power load, low for large systems, a high value for small systems." It said reserve spare capacity, entirely based on the system operation safety, reliability considerations, relatively speaking; the economy is only a secondary factor. Emergency reserve should ensure that no loss of load when the system is a major power shortage $\mathrm{N}-1$ failures and network units in the first FM reliable operation, the unit secondary frequency can effectively continue. Load reserve to balance the load forecast error, less than $2 \%$ of the maximum expected load of the day. Operating reserve for the emergency reserve and load reserve sum. Interconnected grid should reflect the alternate sharing case of an accident can achieve full network backup shared by flash support.

\section{Summary}

In this paper, East China Power Grid spare capacity market trading patterns carried out in-depth research, considering the regional electricity market already have the condition, and numerical example is proposed transaction model for regional reserve market. Recommends two market a regional unified backup market, concentrated on obtaining a replacement resources, but satisfy the minimum alternate partition needs; using alternate bidding clearing all involved in day-ahead market; the market-clearing model uses joint optimization, target-oriented energy, alternate total 
operating costs the minimum; alternate service costs and electricity costs by volume were settled, spare the expense of all access units apportioned in accordance with its actual Internet capacity. When the backup needs of research models in this paper are based on the case when the two systems interconnected, extended to three or more systems interconnection, reliability probability model to be treated will be more three-dimensional model, but with the way the system interconnect these systems and the mutual support between priorities related.

\section{Reference}

[1]Van d B P P J, Jokic A, Frunt J, et al. Incentives-based ancillary services for power system integrity[J]. Proceedings of International Conference on the European Energy Market, 2009:1 - 7.

[2]Taylor C W, Bbattacharya K, Zhong J. Discussion of "Reactive power as an ancillary service" [and closure][J]. Power Systems IEEE Transactions on, 2002, 17.

[3]Doi H, Serizawa Y, Tode H, et al. Simulation study of QoS guaranteed ATM transmission for future power system communication[J]. IEEE Transactions on Power Delivery, 1999, 14(2):342 348.

[4]Overbye T J, Sauer P W, Marzinzik C M, et al. A user-friendly simulation program for teaching power system operations[J]. Power Systems IEEE Transactions on, 1995, 10(4):1725 - 1733.

[5]Kabouris J, Vournas C D. Designing controls to increase wind power penetration in weakly connected areas of the Hellenic interconnected system[C] Power Engineering Society General Meeting, 2003, IEEE. IEEE, 2003.

[6]Ruiz P A, Sauer P W. Valuation of Reserve Services[C] 2014 47th Hawaii International Conference on System Sciences. IEEE Computer Society, 2008:180.

[7] Carvajal-Quintero S, Arango-Manrique A, Arango-Aramburo S, et al. A Study of incentives to increase the use of DG in Colombia based on a System Dynamics modeling[J]. Ingeniería E Investigación, 2011, 31(10):págs. 58-65. 